\title{
Covid 19 Pandemisinde Sağlık Sistemi Gelişmelerinin Etkinliğinin Ölçülmesi: G-20 Üzerine Bir İnceleme
}

\author{
Ahmet SEL ${ }^{1}$
}

Öz

Makale Türü
Araştırma Makalesi
22.05.2021
Kabul Tarihi
11.07.2021
DOI
10.53306/klujfeas.941041

Toplum sağlığının en önemli göstergelerinden birisi sağlık hizmetlerinin kalitesi ve işlevselliğidir. Geçmiş dönemde yapılan yatırım ve gelişmelerin sağlık sistemindeki etkisi Covid 19 pandemisinde daha açık gözlenebilmiştir. Bu çalışmada G-20 ülkelerinin sağlık sistemi gelişmelerinin Covid 19 performansı değerlendirilmiştir. Dünya Bankası veri tabanında sağlık başlığı altında yer alan 5 gösterge girdi iken Covid 19 bağlantılı ölüm, iyileşen ve test sayıları çıktı olarak kullanılmıştır. Girdi değişkeni olan sağlık göstergeleri için 2000-2018 yılları arasındaki 19 yıllık verilerin ortalama değerleri kullanılmıştır. Uygulamada veri zarflama analizi kullanılarak çıktı yönelimli sabit ve değişken getiri yöntemleri ile ölçek etkinlik skorları ve süper etkinlik değerleri hesaplanmıştır. Analiz sonucunda ölçek etkinlik skorlarına göre Amerika, Arjantin, Brezilya, Çin, Fransa, İngiltere ve Türkiye etkin olarak bulunmuştur.

Anahtar sözcükler: covid 19, sağlık sistemi, veri zarflama analizi, G20, etkinlik ölçümü 


\title{
Measuring the Efficiency of Health System Developments in the Covid 19 Pandemic: A Study on the G-20
}

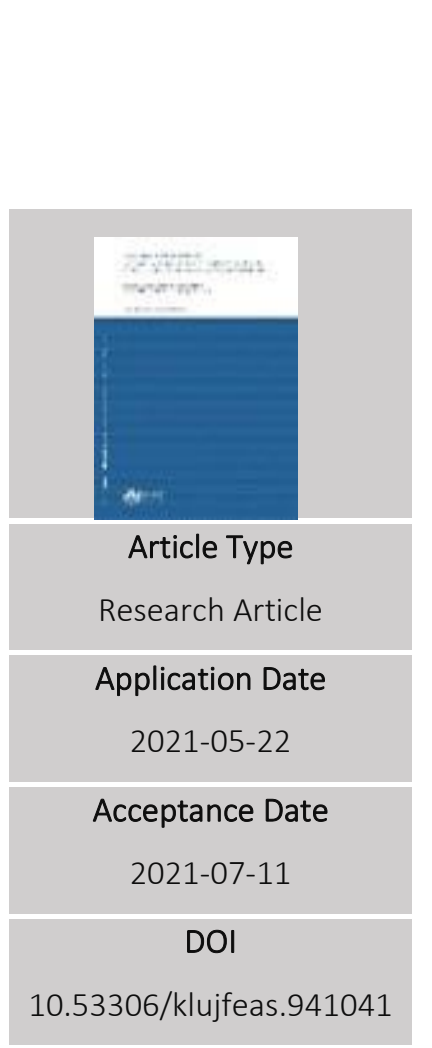

\begin{abstract}
The quality and functionality of health services is an important indicator of public health. The impact of previous investments and developments on the health system could be seen more clearly in the Covid 19 pandemic. The Covid 19 performance of the health system developments of G-20 countries was evaluated in this study. While 5 health-related indicators from the World Bank database were input, Covid 19-related deaths, healed, and test numbers were used as outputs. They are the average values of 19 years of data for health indicators, which are input variables, between 2000 and 2018 . In practice, scale efficiency scores and super efficiency values were computed using data envelopment analysis and output-oriented fixed and variable return methods. According to the scale efficiency scores, America, Argentina, Brazil, China, France, England, and Turkey were found to be effective.
\end{abstract}

Key Words: covid 19, health system, data envelopment analysis, G20, effectiveness measurement

2 PhD., Ministry of Education, selahmet43@gmail.com, ORCID: 0000-0003-1914-5878 


\section{Giriş}

Sağlık sistemlerinin temel amacını doğrudan sağ|ı̆̆ı geliştirmek, iyileştirmek ya da korumak olan her türlü faaliyet, kurum ve kaynakların tamamı içerir. Sağlık sistemleri bireylerin sağ|ığını iyileştirir ve geliştirirken bireylere insani değerler çerçevesinde hizmet verme ve bireyleri hastalıkların sebep olduğu maliyetlerinden koruma sorumlulukları da bulunmaktadır. Bundan dolayı sağlık sistemleri, iyi işleyen bir finansman mekanizmasına, eğitimli işgücüne, doğru zamanda elde edilmiş güvenilir bilgiye, yeterli donanıma sahip tesis ve lojistik desteğe intiyaç duymaktadır (WHO, 2000).

Günümüzde ülkelerin kalkınmışlık derecesinin ve sosyoekonomik gelişmişlik düzeylerinin belirlenmesinde ekonomik, sosyal ve kültürel etmenlerin yanı sıra sağlık sistemlerinin yapısı da önemli bir ölçüt olarak kullanılmaktadır (Temür ve Bakırcı, 2008, s. 262). Toplumsal yapı içerisinde ilerlemenin ve gelişmenin ana temelini sağ ık hizmetlerinin yapısı belirlemektedir. Bireyleri her açıdan sağ|ıklı yetişen toplumların eğitim ve teknoloji alanında çağı takip etmeleri kolay hale gelmektedir. Özellikle sağlık alanında teknoloji üreten ve geliştiren ülkelerin diğer alanlarda da yetkinliklerinin üst düzeyde olduğu görülmektedir.

Bir toplumda sağlık sistemlerinin ana amacı, sağlık düzeyinde iyileştirmeler gerçekleştirmektir. Toplumun sağlık düzeyini eğitim ve gelir seviyesi başta olmak üzere etkileyen farklı etkenler de bulunur. Genellikle eğitim ve gelir seviyeleri birbirine benzer ülkelerin sağlık çıktılarında farklılıkların bulunması, bu ülkelerin sağlık sistemlerinin performansı ile açıklanabilir. Ayrıca sağıı sistemlerinin içerikleri, tasarımları ve yönetimlerindeki değişiklikler farlı sağlık çıktılarına neden olmaktadır. Bundan dolayı, ülkedeki tüm karar vericilerin sağlık sistemi performansındaki değişiklikleri değerlendirmeesi, performansı etkileyen etkenleri incelemesi ve sonuçları iyileştirecek politikaları benimsemeleri gerekmektedir. Sağlık sistemlerinin performansı değerlendirilirken elde edilen karşılaştırılabilir ve anlamlı bilgiler hem ulusal hemde uluslararası düzeyde uygulanacak sağlık politikaları için bilimsel temeli güçlendirecektir (Murray ve Frenk, 2000, s. 717).

Her ülkenin ekonomik, politik ve kültürel durumuna göre oluşturduğu sağlık politikaları; doğumda beklenen yaşam süresini yükseltmek, bebek ölüm oranlarını azaltmak ve topluma çağdaş teknoloji içeren, yeterli kapasiteye ve yetkinliğe sahip kaliteli sağlık hizmeti sunmak kısacası sağlıklı bir toplum oluşturmak gibi hedefler taşımaktadır (Kocaman vd., 2012, s. 15). Sağlık sistemlerinin performanslarının değerlendirilmesinde sağlık seviyesini ortaya koyan göstergelere ihtiyaç duyulmaktadır. Dünya Bankası (World Bank), Ekonomik İşbirliği ve Kalkınma Örgütü (OECD), Dünya Sağlık Örgütü (WHO) gibi kuruluşlar sağlık göstergeleri olarak adlandırılan ve sağlık politikalarını ile düzeyini ortaya koyan standart ve sayısal veriler sunmaktadır. Karşılaştırmalar ve incelemeler sırasında araştırmanın konusuna uygun olacak şekilde verilere bu kuruluşların açık erişimli veri tabanlarından ulaşılabilmektedir.

Covid 19 hastalığı Çin'in Wuhan şehrinde 31 Aralık 2019'da ilk defa görülmüştür. Korona virüsün önceki türleri soğuk algınlığı şeklinde insanları etkilerken bu salgında ciddi rahatsızlıklara neden olduğu belirlenmiştir. Özellikle hastalarda tedaviye yanıt vermeyen 
SEL, Measuring the Efficiency of Health System Developments in the Covid 19 Pandemic: A Study on the G-20, 181202.

zatürre şeklinde kendini gösteren virüsün; SARS-CoV-2 şeklinde isimlendirilen yeni bir tür olduğu belirlenmiştir. Tam olarak hangi hayvandan bulaştığı bulunamayan virüs için insandan insana hızlı bir şekilde bulaştığı tespit edilmiştir. Salgın hızının artması ve bulaşmanın önlenememesinden dolayı WHO tarafından 11 Mart 2020 tarihinde küresel salgın ilan edilmiştir (Arslan, 2020, s. 4).

Covid 19 salgının hızlı yayılımı tüm ülkeleri etkilerken pandemi konusunda hazırlıklı olmayan ülkeler için ağır şartlar oluşturmuştur. Sağlık sistemlerinin yetersiz kalmasından korkan yöneticiler maske ve mesafe önlemleri yeterli olmayınca tam kapanma durumuna geçiş yapmışlardır. Ülkelerin bu süreçte sadece sağlık sistemleri değil ekonomik ve sosyal gelişmişlik düzeylerinin de pandemi yönetiminde etkin olduğu görülmüştür. Dünya Bankası veri tabanında yer alan sağlık göstergeleri ülkelerin sağlık sistemlerinin değerlendirilmesinde bu açıdan geniş bir alan sunmaktadır. Türkiye'nin de içinde bulunduğu G-20 ülkelerinin geçmiş dönem sağlık göstergeleri kullanılarak sağlık sistemlerinin Covid 19 pandemi sürecindeki etkinliği incelenmiştir.

Türkiye'de ilk Covid-19 vakası 11 Mart 2020 tarihinden meydana gelmiştir. Pandemi sürecinde özellikle bilgi paylaşımı konusunda tartışmalar olsa da genel anlamda sağlık sisteminin düzenli çalıştığı görülmüştür. Özellikle Türkiye'de pandemi sürecinde uluslararası örgütler ile ilişkiler başta olmak üzere düzenli bir yönetim örneği gösterilmiştir. Süreçte sağlık sistemin çökmesi ya da hastaların tedaviye ulaşamadığı durumlara, diğer ülkelerin aksine Türkiye'de çok fazla yaşanmamıştır (Türk Tabibler Birliği, 2020, s. 44).

Pandemi döneminde ülkelerin sağlık sistemlerinin sürece yanıtları başarı performansları olarak görülmüştür. Covid 19 hastalığına yakalanmış bireyler için ölüm ve iyileşme sayıları ile hastalığın yayılmasını önleyecek olan enfekte bireylerin tespiti bu süreçte büyük önem taşımaktadır. Hastalıklı bireylerin tespiti yeni yapılan testler ile mümkün olmasına rağmen, hastalıklı bireyler üzerindeki tedavi yöntemleri geçmiş dönem ülkelerin sağlık sistemi gelişmelerine bağ|ı olduğu görülmüştür.

Bu çalışmada G-20 ülkelerinin 2000-2018 yıllarındaki sağlık göstergeleri ortalamaları kullanılarak Covid 19 performansları değerlendirilmiştir. Uygulamada G-20 ülkelerinin seçilme nedeni, dünya ekonomisinin yaklaşık \% 85'ini, ticaretinin \% 75'ini ve nüfusunun 2/3'ünü temsil etmekte olan G-20, farklı kıtalardan gelişmiş ve yükselen ekonomileri aynı platformda bir araya getiren, kapsayıcı yapısıyla uluslararası ekonomik düzlemde profili giderek yükselen bir oluşum olarak kendisini göstermesidir (Dışişleri Bakanlığı, 2020). Çalışmada girdi olarak; mevcut sağlık harcamaları (GSYiH göre \%), en azından temel sağlık hizmetlerini kullanan kişiler (nüfusun \%), hastane yatakları (1.000 kişi başına), hemşireler ve ebeler (1000 kişi başına), hekimler (1000 kişi başına) ve çıktı olarak milyon kişi başına ölüm oranı, milyon kişi başına iyileşen oranı ve milyon kişi başına test oranı kullanılmıştır. Etkinlik analizi için çıktı yönelimli Charnes, Cooper, Rhodes (CCR) ve değişken ölçekli Banker, Charnes, Cooper (BCC) yöntemleri kullanılmıştır. Elde edilen CCR ve BCC değerleri ile etkinlik ölçek skorları ve süper etkinlik değerleri hesaplanmıştır. Sonuç kısmında etkin olmayan ülkeler için iyileştirme önerileri sunulmuştur. 


\section{Literatür İncelemesi}

Çalışmadaki alt başlıklar yazım kılavuzunda belirtilen başlık özelliklerine uygun olarak yazılmalıdır. Literatürde ülkelerin performanslarının değerlendirilmesini konu alan çalışmalar incelendiğinde; Hadad, Hadad ve Simon-Tuval’ın (2013) çalışmalarında VZA ile, OECD ülkelerinin sağlık sistemlerini incelemiştir. Çalışmada sonuç olarak istikrarlı bir ekonomiye sahip olan ülkelerin sağlık sistemlerininde yeterli düzeyde olduğu görülmüştür. Kaya, Samut ve Cafri (2016) çalışmalarında, OECD ülkeleri için VZA ile hastane verimliliklerini değerlendirmiştir. Sonuç olarak, hastane verimliliğinde gelirlerin, eğitimin ve özel hastane sayısının olumlu etkisi bulunurken, sağlık giderleri konusunda hastane sayısının verimliliği olumsuz etkilediği görülmüştür. Yeşilyurt ve Salamov (2017) çalışmalarında, VZA ve Tobit Analizi yöntemleri ile Türkiye, Azerbaycan, Kazakistan, Türkmenistan, Kırgızistan ve Özbekistan devletleri sağlık sistemlerinin etkinliklerinin ve etkinliğe etki eden faktörlerinin karşılaştırmalı olarak değerlendirilmiştir. Girdi değişkenleri; "ülkelerin 1000 kişi başına doktor sayısı" ve "hastane yatak sayısı" ve "sağlık harcamalarının GSYiH içerisinde payları", çıktı değişkenleri olarak ise "ortalama yaşam süresi" ve "100 000 kişi başına düşen ameliyat sayıları" etkinlik analizinde kullanılmıştır. Çalışmada CCR ve BCC modelleri etkinlik analizleri sonucunda Kırgızistan ve Özbekistan`ın etkinlik skorlarının 1 'in altında çıkmıştır. CCR yöntemi ile elde edilen skorlara göre yapılan Tobit analizinde her iki çıktının etkinlik üzerinde pozitif etkisinin olduğu fakat "ortalama yaşam süresi" çıktısının anlamsız, "yüz bin kişi başına ameliyat sayısının" \%10 anlamlılık düzeyinde anlamlı olduğu sonucuna varılmıştır. BCC yöntemi ile elde edilen etkinlik skorlarına göre yapılmış Tobit analizinde her iki çıktı katsayılarının etkinlik üzerinde pozitif etkisinin olduğu fakat alınan sonuçların \%5 anlamlılık düzeyinde anlamsız olduğu sonucuna varılmıştır. Boz ve Önder (2017), çalışmalarında OECD ülkelerinin sağlık sisteminin etkinlik analizi 2000 ve 2013 yılı verilerine göre VZA yöntemiyle incelemişlerdir. Analiz sonucunda 34 OECD üyesi ülkeden 2000 yılında 15 ülkenin etkin olduğu, 2013 yılında ise bu sayının 13'e düştüğü tespit edilmiştir. 2000 yılında etkin olan ülkeler; Şili, Finlandiya, Yunanistan, İzlanda, İrlanda, İsrail, Japonya, Meksika, Hollanda, Yeni Zelanda, Polonya, Güney Kore, İsviçre, Türkiye ve ABD şeklindedir. 2013 yılında ise etkin olan ülkeler; Avustralya, Şili, Estonya, Finlandiya, Yunanistan, İzlanda, İsrail, Meksika, Polonya, Güney Kore, Slovenya, Türkiye, ABD şeklindedir. Konca, Gözlü ve Çakmak (2019), G-20 ülkelerinin 2012-2014 yılları arasındaki kamu, özel ve cepten sağlık harcamalarından oluşan toplam sağlık harcamalarının etkinliği VZA kullanarak incelemiştir. Etkinsiz olarak belirlenen ülkelerden en düşük etkinlik skorlarına sahip olan ülkeler; $A B D$, Kanada, Brezilya ve Almanya olarak belirlenmiştir. Ölçek etkinliklerinin en düşük olduğu ülkeler; Kanada, Arjantin ve Avustralya olarak belirlenmiştir. Ayrıca Teleş, Çakmak ve Konca (2018), çalışmalarında 2014 yılı sağlık göstergerlerini kullanarak Avrupa Birliği döngüsündeki ülkelerin sağlık sistemlerinin verimlilik performansları VZA ile karşılaştırılmıştır. Karşılaştırma yapılmadan önce kümeleme analizi yapılarak karşılaştırılan ülkeler sınıfladırılmıştır. Analiz sonuçlarına göre, birinci kümede yer alan ülkelerin \% 56,25'i, ikinci kümede yer alan ülkelerin \% 65'i verimli bulunmuştur. Konca ve Demirci (2019), çalışmalarında Türkiye ile G20 ülkelerinin sağlık sistem performansları Malmquist Toplam Faktör Verimliliği (MTFV) Endeksi yardımıyla karşılaştırmıştır. Analiz sonuçlarına göre Türkiye; 2000-2010, 2010-2015 
SEL, Measuring the Efficiency of Health System Developments in the Covid 19 Pandemic: A Study on the G-20, 181202.

ve 2000-2015 dönemlerinde sağlık sisteminde verimlilik artışı gösteren ülkeler arasındadır. Şahinbaş, Konca ve Yetim (2019) çalışmalarında, OECD ülkeleri için sağlık hizmetlerinde etkinlik düzeylerini VZA ile incelemiştir. Sonuç olarak, Meksika ve Türkiye gibi ülkeler için sağlık hizmetlerinde etkinliklerinin çok yüksek olduğu görülmüştür.

Covid 19 konusunda yapılan çalışmalar incelendiğinde Shirouyehzad, Jouzdani ve Khodadadi Karimvand (2020), VZA ile COVID-19 salgınına karşı mücadelede verimlilik düzeyini araştırmıştır. Analiz sonucunda Singapur, Vietnam ve Belçika'nın yüksek verimliliğe sahip oldukları görülmüştür. Ayrıca Avrupa ülkeleri için en verimli ülke Belçika iken en az verimin Italya'da olduğu belirlenmiştir. Orta Doğu'da bulaşma kontrolünde İran, tıbbi tedavide Mısır’ın etkili olduğu görülmüştür. Selamzade ve Özdemir (2020) çalışmasında, Covid 19 salgını için OECD ülkelerinin etkinlik düzeylerini VZA ile araştırmıştır. Çalışmada CCR ve BCC yöntemleri ile süper etkinlik değerleri kullanılmıştır. Analiz sonucunda CCR yönteminde 8, BCC yönteminde ise 11 ülkenin etkin olduğu görülmüştür. Süper etkinlik skorları için Slovakya (CCR) ve İzlanda (BCC) en etkin olan ülkeler olarak belirlenmiştir. Ayrıca ülkelerin gelişmişlik düzeyi ve sağlık sistemlerinindeki çalışan sayısının fazla olması daha az vaka ve ölüm sayısına neden olmuştur.

\section{Veri Zarflama Analizi}

VZA, performans değerlendirilmesinde etkili olarak kullanılan yöntemlerden biridir. Ölçeğe göre sabit getiri(CCR) veya ölçeğe göre değişken getiri(BCC) olmak üzere iki ana yaklaşıma sahiptir. CCR modelinde girdilerde meydana gelen artışlar sonucunda çıktılardaki artış incelenmektedir. BCC modelinde ise girdilerdeki artış sonucunda çıktılarda meydana gelebilecek daha az veya çok artışın görülmesi incelenir. Ayrıca her iki yaklaşım içinde yönelim türüne göre girdi, çıktı ve yönelimsiz şeklinde alt bölümleri mevcuttur. VZA için çalışma modelleri Şekil 1'de görülebilir.

Şekil 1. VZA Modelleri (Özden, 2008)

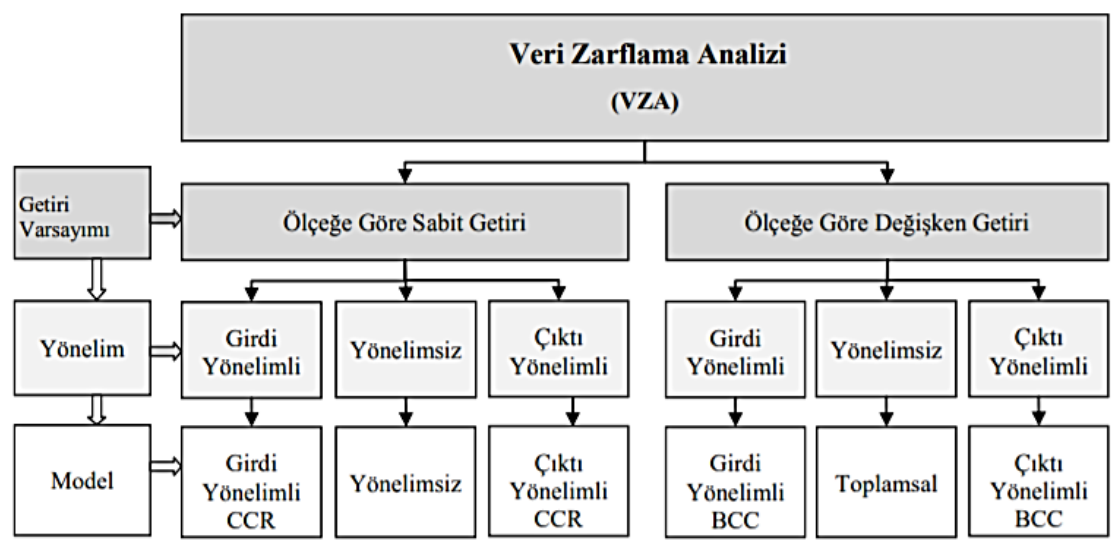


SEL, Covid 19 Pandemisinde Sağlık Sistemi Gelişmelerinin Etkinliğinin Ölçülmesi: G-20 Üzerine Bir Inceleme, 181202.

VZA modeli verimlilik ve etkinliğin ölçülmesini sağlayan doğrusal programlama yöntemlerinden biridir. CCR modeli oluşturulurken n sayıda Karar Verici Birim (KVB) olması durumunda her $\operatorname{KVB}_{j}(j=1, \ldots, n)$ için $m$ sayıda girdi $\tilde{X}_{j}=\left(X_{1 j}, X_{2 j}, \ldots, X_{m j}\right)^{\top}>0$ olmak üzere $s$ sayıda $\tilde{Y}_{j}=\left(Y_{1 j}, Y_{2 j}, \ldots, Y_{m j}\right)^{\top}>0$ çıktısı ürettiği kabul edilir. CCR modeli her KVB için ağırlıklı girdilerin sonucunda elde edilen ağırlıklı çıktıların oranını maksimize edecek şekilde negatif olmayan en iyi $U_{r k}(r=1 ; 2 ; \ldots ; S)$ ve $V_{i k}(i=1 ; 2 ; \ldots, m)$ ağırlıklarının elde edilmesini sağlar (Charnes, Cooper ve Rhodes, 1978, s. 433).

$$
\theta=\frac{\sum_{r=1}^{s} u_{r} y_{r j}}{\sum_{i=1}^{m} v_{i} x_{i j}}
$$

Modeller girdi ve çıktı yönelimli olmakla iki farklı şekilde formülize edilmiştir. Girdi yönelimli analiz modelleri, verilmiş çıktı düzeylerini korumakta ve bu yolla kullanılan girdi miktarını en aza indirmeyi hedeflemektedir. Çıktı yönelimli analizler ise eldeki girdi miktarlarını değiştirmeden, çıktıların maksimize edilmesinin araştırılması amacıyla yapılmaktadır (Cooper vd., 2011, s. 41). Girdi yönelimli CCR yöntemi ile VZA yapılırken formülün payda değeri 1'e eşitlenir. Çıktı yönelimli CCR yöntemi ile VZA yapııırken de pay değeri 1'e eşitlenir. Çalışmada G-20 ülkeleri için sağlık göstergesi ortalamaları olan 5 girdi değerine karşıılık Covid-19 performansları ölüm, iyileşen ve test sayıları çıktıları ile değerlendirilmiştir. Uygulamada girdi değerleri geçmiş dönemlerin bir değerlendirmesi olduğundan dolayı güncel durum incelendiğinden çıktı yönelimli CCR modeli kullanılmıştır. Çıktı yönelimli CCR modeli ile etkinlik analizinin yapılması için doğrusal programlama modeli şu şekildedir (Cooper vd., 2011, s. 73):

$\operatorname{Max} \theta_{\mathrm{CCR}}$

KIsItlar: $\sum_{j=1}^{n} \lambda_{j} x_{i j}-x_{i 0} \leq 0 ; \sum_{j=1}^{n} \lambda_{j} y_{r j}-\varphi y_{r 0} \geq 0 ; \lambda j \geq 0$

Bu primal ve dual problemlerinde,

$x_{i j}:$ j. KVB için kullanılan i. girdi değeri

$y_{r j}:$ j. KVB tarafında üretilen $r$. çıktı değeri

$x_{i 0}$ : Sıfırıncı KVB için kullanılan i. girdi değeri

$y_{r 0}$ : Sıfırıncı KVB tarafında üretilen $r$. çıktı değeri

olarak tanımlanmaktadır. Çıktı yönelimli etkinlik skoru elde edilirken " $1 / \sum_{i=1}^{m} v_{i} x_{i j}$ " olduğu için elde edilen $\theta$ değerine bağlı olarak etkinlik yorumları şu şekildedir:

$\theta=1$ ise ve artıkların değerleri sıfırsa KVB etkindir.

$\theta>1$ ise KVB etkin değildir.

Banker, Charnes ve Cooper'ın geliştirdiği BCC modelinde CCR modeline ek olarak konvekslik kısıtı $\left(\sum_{j=1}^{n} \lambda_{j}=1\right)$ eklenerek oluşturulur. Çıktı yönelimli BCC modeli kullanılarak etkinlik hesaplanması formülü şu şekildedir (Banker vd., 1984, s. 1090): 
SEL, Measuring the Efficiency of Health System Developments in the Covid 19 Pandemic: A Study on the G-20, 181202.

$\operatorname{Max} \theta_{\mathrm{BCC}}$

KIsItlar: $\sum_{j=1}^{n} \lambda_{j} x_{i j}-x_{i 0} \leq 0 ; \sum_{j=1}^{n} \lambda_{j} y_{r j}-\varphi y_{r 0} \geq 0 ; \sum_{j=1}^{n} \lambda_{j}=1 ; \lambda j \geq 0$

KVB için CCR ve BCC etkinlikleri hesaplandıktan sonra ölçek etkinlikleri hesaplanmıştır.

Ölçek $E$ tkinliği $(O ̈ E)=\theta_{C C R} / \theta_{B C C}$

ÖE değeri için CCR ve BCC etkinlik skorları her iki durumda da bire eşitse KVB için tam etkin oldukları söylenir.

VZA uygulamasında Süper Etkinlik skorları hesaplanarak etkin olan KVB'ler arasında en fazla etkin olanları tespit edilir (Seiford ve Thrall, 1990, s. 16). Çıktı yönelimli CCR ve BCC modellier için süper etkinlik değerleri şu şekilde hesaplanır:

Çıktı yönelimli CCR modeli Süper Etkinlik skoru:

$\operatorname{Max} \rho$

KIsItlar: $\sum_{j=1}^{n} \lambda_{j} x_{i j}-\rho x_{i 0} \leq 0 ; \sum_{j=1}^{n} \lambda_{j} y_{r j}-y_{0} \geq 0 ; \lambda j, \rho \geq 0$ ve $j \neq 0$

Çıktı yönelimli BCC modeli Süper Etkinlik skoru:

$\operatorname{Max} \rho$

Kısıtlar: $\sum_{j=1}^{n} \lambda_{j} x_{i j}-\rho x_{i 0} \leq 0 ; \sum_{j=1}^{n} \lambda_{j} y_{r j}-y_{0} \geq 0 ; \sum_{j=1}^{n} \lambda_{j}=1 ; \lambda j, \rho \geq 0$ ve $j \neq 0$

\section{Uygulama}

VZA yöntemi uygulayarak performans değerlendirilmesinde $\mathrm{R}$ programlama dili altında "deaR" kütüphanesi kullanışmıştır(Charnes vd., 1997,s. 332). Uygulamada girdi ve çıktı olarak kullanılan değişkenler ile $\mathrm{R}$ programında kullanılan modüller bu bölümde gösterilmiştir.

G-20 ülkeleri için çalışmaya dahil olan ülkeler ve kodları Tablo 1'de gösterilmiştir. G-20 ülkeleri içinde Avrupa Birliği bir ülke şeklinde yer almaktadır. Ancak çalışmada sadece ülkeler değerlendirildiğinden dolayı 19 ülke uygulamaya dahil edilmiştir.

Tablo 1. G-20 Ülkeleri

\begin{tabular}{llll}
\hline Kod & Ülke & Kod & Ülke \\
\hline DEU & Almanya & IND & Hindistan \\
USA & Amerika Birleşik Devletleri & GBR & Birleşik Krallık \\
ARG & Arjantin & ITA & Italya \\
AUS & Avustralya & JPN & Japonya \\
BRA & Brezilya & CAN & Kanada \\
\hline
\end{tabular}


SEL, Covid 19 Pandemisinde Sağlık Sistemi Gelişmelerinin Etkinliğinin Ölçülmesi: G-20 Üzerine Bir Inceleme, 181202.

\begin{tabular}{lll}
\hline CHN Çin & MEX Meksika \\
IDN Endonezya & RUS Rusya Federasyonu \\
FRA Fransa & SAU Suudi Arabistan \\
ZAF Güney Afrika & TUR Türkiye \\
KOR Kore Cumhuriyeti & & \\
\hline
\end{tabular}

Dünya Bankası veritabanı altında sağlık göstergeleri başlığı altında 250 adet değişken bulunmaktadır. 2000-2018 yılları arasında oran ile yüzde formatında yer alan, incelenen ülkelerin tamamında bulunan ve eksik veriler içermeyen 5 farklı göstergenin ortalama değerleri girdi değişkeni olarak alınmıştır. Kullanılan değişkenler ve açıklamaları Tablo 2'de gösterilmiştir. Çıktı değişkenleri değerleri ise "https://www.worldometers.info/coronavirus/\#countries" sayfasında yer alan açık erişimli değerlerdir.

Tablo 2. Kullanılan Değişkenler ve Açıklaması

\begin{tabular}{lll}
\hline Kod & Değer & Açıklaması \\
\hline G-1 & $\max$ & Mevcut sağlık harcamaları (GSYiH göre \%) \\
G-2 & $\max$ & En azından temel sağlık hizmetlerini kullanan kişiler (nüfusun \%) \\
G-3 & $\max$ & Hastane yatakları (1.000 kişi başına) \\
G-4 & $\max$ & Hemşireler ve ebeler (1000 kişi başına) \\
G-5 & $\max$ & Hekimler (1000 kişi başına) \\
C-1 & $\min$ & Milyon kişi başına ölüm oranı \\
C-2 & $\max$ & Milyon kişi başına iyileşen oranı \\
C-3 & $\max$ & Milyon kişi başına test oranı \\
\hline
\end{tabular}

Kaynak: Dünya Bankası, Sağlık Göstergeleri, (2020).

Girdi ve çıktı değişkenleri için "min" değerli olanların tersi alınarak uygulamaya uygun hale getirilmiştir. Çıktı değişkenleri; ülkelerin 15 Mayıs 2021 tarihi itibariyle Covid-19 sonucunda meydana gelen ölüm, iyileşen ve test sayılarının milyon kişi başına oranlarıdır. Elde edilen değerler için girdi ve çıktı değişkenlerinin değerleri Tablo 3’te gösterilmiştir. 
SEL, Measuring the Efficiency of Health System Developments in the Covid 19 Pandemic: A Study on the G-20, 181202.

Tablo 3. Girdi ve Çıktı Değerleri Tablosu

\begin{tabular}{lcccccccc}
\hline Ülke & G-1 & \multicolumn{1}{c}{ G-2 } & G-3 & G-4 & G-5 & C-1 & \multicolumn{1}{c}{ C-2 } & \multicolumn{1}{c}{ C-3 } \\
\hline DEU & 10.58 & 99.22 & 0.83 & 1.10 & 0.37 & 0,001 & 38986 & 691451 \\
USA & 15.54 & 99.97 & 0.30 & 0.99 & 0.25 & 0,001 & 81453 & 1398370 \\
ARG & 8.14 & 91.69 & 0.45 & 0.20 & 0.35 & 0,001 & 64403 & 270696 \\
AUS & 8.45 & 99.99 & 0.40 & 1.07 & 0.31 & 0,028 & 1122 & 679738 \\
BRA & 8.36 & 81.15 & 0.24 & 0.58 & 0.18 & 0,000 & 65751 & 219617 \\
CHN & 4.42 & 71.48 & 0.35 & 0.15 & 0.15 & 0,310 & 60 & 111163 \\
IDN & 2.70 & 58.07 & 0.08 & 0.12 & 0.02 & 0,006 & 5786 & 56084 \\
FRA & 10.80 & 98.66 & 0.69 & 0.89 & 0.34 & 0,001 & 77684 & 1240933 \\
ZAF & 7.35 & 67.96 & 0.28 & 0.43 & 0.07 & 0,001 & 25405 & 184922 \\
KOR & 5.86 & 100.00 & 1.00 & 0.49 & 0.19 & 0,027 & 2364 & 181632 \\
IND & 3.66 & 39.02 & 0.08 & 0.14 & 0.07 & 0,005 & 14937 & 224903 \\
GBR & 8.14 & 99.12 & 0.32 & 0.64 & 0.25 & 0,001 & 62694 & 2478248 \\
ITA & 8.55 & 98.77 & 0.36 & 0.63 & 0.41 & 0,000 & 61216 & 1038350 \\
JPN & 9.18 & 99.95 & 1.37 & 1.04 & 0.22 & 0,011 & 4636 & 103182 \\
CAN & 9.83 & 99.57 & 0.30 & 0.98 & 0.22 & 0,002 & 32261 & 877832 \\
MEX & 5.64 & 83.85 & 0.15 & 0.25 & 0.20 & 0,001 & 14585 & 52490 \\
RUS & 5.09 & 87.13 & 0.90 & 0.83 & 0.40 & 0,001 & 31150 & 911713 \\
SAU & 4.30 & 99.17 & 0.23 & 0.41 & 0.20 & 0,005 & 11812 & 507779 \\
TUR & 4.78 & 90.83 & 0.25 & 0.25 & 0.16 & 0,002 & 57947 & 595199 \\
\hline
\end{tabular}

Tabloda yer alan C-1 minumun değerli olduğundan dolayı (1/C-1) şeklinde elde edilen ters değerine yer verilmiştir.

VZA yapılırken özellikle paket programlar kullanıldığı görülmüştür. R programlama dili kullanılarak yapılan analiz için uygulama adımları sırasıyla gösterilerek sonraki çalışmalarda araştırıcılara yol göstermesi istenmiştir. Öncelikle "install" komutu kullanılarak kütüphane indirilmiş ve daha sonra içe aktarılmıştır.

$>$ install.packages("deaR")

library("deaR") 
SEL, Covid 19 Pandemisinde Sağlık Sistemi Gelişmelerinin Etkinliğinin Ölçülmesi: G-20 Üzerine Bir Inceleme, 181202.

Uygulamada kullanılacak veriler Excel dosyasında bulunduğundan dolayı "File" sekmesinden "Import Dataset" tıklanarak "From Excel" olarak seçilmiştir. Dosya "veri" olarak adlandırıldığından dolayı uygulamaya uygun olacak şekilde veri yeniden "datavza" adında yeniden tanımlanmıştır. Modülde "ni" girdi sayısı iken "no" çıktı sayısıdır.

$$
\text { datavza<-read_data(veri,ni=5,no=3) }
$$

Uygun hale gelen veri için öncelikle çıktı yönelimli CCR analizi "model_basic()" modülü ile yapılmıştır. Modülde "dmus" ülke isimlerinin yer aldığı sütun iken "rts" yöntemin belirlenmesini gösterir. Ayrıca modüle girdi ve çıktı yönelimli VZA uygulanmak istenirse girdi için " orientation = "io" " çıktı içinde " orientation = "oo" " sorguları eklenmektedir.

crs = ölçeğe göre sabit getiri (CCR)

vrs = değişken ölçeğe göre getiri (BCC)

$>$ result_crs <- model_basic(datavza, dmus=1, "orientation = "oo", rts="crs")

Elde edilen sonuçlar Excel dosyası şeklinde çıktı alınması için "summary()" modülü kullanılmıştır. Çıktı dosyas R programında açılan çalışma dosyası içinde oluşacaktır.

$>\operatorname{summary}($ result_crs, exportExcel $=$ TRUE, filename $=$ NULL)

BCC hesaplanması için uygulama modülünde sadece "rts" sorgusu "vrs" olarak değiştirilir.

$>$ result_vrs <- model_basic(datavza, dmus=1, " orientation = "oo", rts="vrs")

$>$ summary(result_vrs, exportExcel $=$ TRUE, filename $=$ NULL)

Süper etkinlik değerleri hesaplanırken BCC ve CCR için ayrı ayrı modüller ve çıktılar kullanılmıştır.

$$
\begin{array}{ll}
> & \text { result_csupereff <- model_supereff(datavza, rts = "crs") } \\
> & \text { result_vsupereff <- model_supereff(datavza, rts = "vrs") } \\
> & \text { summary(result_csupereff, exportExcel = TRUE, filename = NULL) } \\
> & \text { summary(result_vsupereff, exportExcel = TRUE, filename = NULL) }
\end{array}
$$

Elde edilen çıktı dosyalarında yer alan sayfaların açıklamaları ise şunlardır:

efficiencies: Verimlilik puanlarını çıkarmak için.

slacks: Giriş ve çıkış değerlerinin artıklarını gösterir.

lambdas: Lambdaları (veya yoğunlukları) çıkarmak için.

targets: Giriş ve çıkış hedef değerlerini gösterir.

returns: Ölçeğe göre getiri türlerini gösterir.

references: Verimsiz değişkenler için referans setini çıkartır. 
SEL, Measuring the Efficiency of Health System Developments in the Covid 19 Pandemic: A Study on the G-20, 181202.

\section{Bulgular}

VZA ölçeğe göre sabit etki olan CCR yöntemi uygulaması sonucunda elde edilen etkinlik değeri, türü ve referans değerleri Tablo 4'te gösterilmiştir. Çıktı yönelimli CCR modeli sonucunda 6 ülke etkin iken 13 ülke etkin olmamıştır.

Tablo 4. CCR Skor, Etkinlik Değeri, Türü ve Referans Değerleri

\begin{tabular}{|c|c|c|c|c|c|c|c|c|c|}
\hline Ülke & Skor & $\begin{array}{l}\text { Etkinlik } \\
\text { Değeri }\end{array}$ & $\begin{array}{l}\text { Etkinlik } \\
\text { Türü }\end{array}$ & $\begin{array}{l}\text { BRA } \\
(4)\end{array}$ & $\begin{array}{l}\mathrm{CHN} \\
(11)\end{array}$ & $\begin{array}{l}\text { FRA } \\
(2)\end{array}$ & $\begin{array}{l}\text { GBR } \\
\text { (9) }\end{array}$ & $\begin{array}{l}\text { TUR } \\
\text { (9) }\end{array}$ & $\begin{array}{l}\text { USA } \\
\text { (3) }\end{array}$ \\
\hline DEU & 0,51 & 1.96 & Azalan & - & - & 0.91 & 0.09 & - & - \\
\hline USA & 1,00 & 1.00 & Sabit & - & - & - & - & - & 1.00 \\
\hline ARG & 1,00 & 1.00 & Sabit & - & - & - & - & - & - \\
\hline AUS & 0,33 & 3.01 & Azalan & - & 0.27 & - & 0.81 & - & - \\
\hline BRA & 1,00 & 1.00 & Sabit & 1.00 & - & - & - & - & - \\
\hline $\mathrm{CHN}$ & 1,00 & 1.00 & Sabit & - & 1.00 & - & - & - & - \\
\hline IDN & 0,84 & 1.18 & Artan & 0.01 & 0.02 & - & - & 0.10 & - \\
\hline FRA & 1,00 & 1.00 & Sabit & - & - & 1.00 & - & - & - \\
\hline ZAF & 0,97 & 1.03 & Artan & 0.17 & - & - & - & 0.26 & - \\
\hline KOR & 0,16 & 6.17 & Artan & - & 0.54 & - & 0.43 & - & - \\
\hline IND & 0,87 & 1.15 & Artan & - & 0.02 & - & 0.01 & 0.14 & 0.10 \\
\hline GBR & 1,00 & 1.00 & Sabit & - & - & - & 1.00 & - & - \\
\hline ITA & 0,87 & 1.15 & Azalan & 0.37 & - & 0.17 & 0.31 & 0.24 & - \\
\hline JPN & 0,09 & 10.97 & Azalan & - & 0.39 & - & 0.22 & 0.22 & 0.30 \\
\hline CAN & 0,52 & 1.92 & Artan & - & 0.01 & - & 0.46 & 0.05 & 0.38 \\
\hline MEX & 0,39 & 2.56 & Artan & 0.28 & - & - & - & 0.32 & - \\
\hline RUS & 0,70 & 1.44 & Artan & - & - & - & 0.46 & 0.27 & - \\
\hline SAU & 0,40 & 2.48 & Artan & - & 0.04 & - & 0.51 & - & - \\
\hline TUR & 1,00 & 1.00 & Sabit & - & - & - & - & 1.00 & - \\
\hline
\end{tabular}

Tablo 4. incelendiğinde Brezilya, Çin, Fransa, İngiltere, Türkiye ve ABD’nin etkin olduğu görülmüştür. En fazla referans alınan ülkeler ise ilk başta Çin (11) olmak üzere İngiltere (9) 
SEL, Covid 19 Pandemisinde Sağlık Sistemi Gelişmelerinin Etkinliğinin Ölçülmesi: G-20 Üzerine Bir Inceleme, 181202.

ve Türkiye'dir (9). En düşük etkinlik ise Japonya'da $(0,09)$ belirlenmiştir. Tablo 5'te CCR yöntemine göre etkin olmayan ülkelerin artık değerleri gösterilmiştir.

Tablo 5. CCR için Değişkenlerin Artık Değerleri

\begin{tabular}{lcccccccc}
\hline Ülke & G1 & G2 & G3 & G4 & G5 & C-1 & \multicolumn{1}{c}{ C-2 } & \multicolumn{1}{c}{ C-3 } \\
\hline DEU & 0.00 & 0.00 & 0.17 & 0.24 & 0.04 & 0.00 & 0.00 & 0.00 \\
AUS & 0.64 & 0.00 & 0.04 & 0.51 & 0.06 & 0.00 & 47563 & 0.00 \\
IDN & 2.00 & 46.11 & 0.04 & 0.09 & 0.00 & 0.00 & 0.00 & 0.00 \\
ZAF & 4.68 & 30.60 & 0.18 & 0.26 & 0.00 & 0.00 & 0.00 & 0.00 \\
KOR & 0.00 & 19.21 & 0.67 & 0.14 & 0.01 & 0.00 & 12282 & 0.00 \\
IND & 1.26 & 13.51 & 0.00 & 0.00 & 0.01 & 0.00 & 0.00 & 0.00 \\
ITA & 0.00 & 0.00 & 0.00 & 0.01 & 0.17 & 0.00 & 0.00 & 0.00 \\
JPN & 0.00 & 0.43 & 1.02 & 0.49 & 0.00 & 0.00 & 0.00 & 0.00 \\
CAN & 0.00 & 11.99 & 0.03 & 0.30 & 0.00 & 0.00 & 0.00 & 0.00 \\
MEX & 1.73 & 31.40 & 0.00 & 0.00 & 0.10 & 0.00 & 0.00 & 120906 \\
RUS & 0.00 & 16.27 & 0.69 & 0.47 & 0.24 & 0.00 & 0.00 & 0.00 \\
SAU & 0.00 & 46.18 & 0.05 & 0.09 & 0.07 & 0.00 & 2460 & 0.00 \\
\hline
\end{tabular}

Tablo 5. incelendiğinde ülkelerin etkin olabilmeleri için gereken girdilerdeki fazlalık ve çıktılardaki azlık değerleri gösterilmiştir. Örneğin birinci satırda yer alan DEU kodlu Almanya'nın G3, G4 ve G5 değişkenleri için fazlalık değerleri sunulmuştur. Almanya'nın etkin olabilmesi için bin kişi başına düşen hastane yataklarını 0.169, hemşire ve ebeleri 0.240 ve hekimleri 0,038 birim daha etkin kullanmalıdır. Diğer ülkeler için de satır değerleri incelenerek aynı yorumlar yapılabilir. Çıktılarda ise Covid 19 hastaları için milyon başına düşen iyileşen oranında Avustralya (47563), Güney Kore (12282) ve Suudi Arabistan'da (2460) artış olması gerekmektedir. Milyon kişi başına düşen test oranında ise Meksika'nın (120906) test sayılarını arttırmasına ihtiyaç vardır.

Ölçeğe göre değişken getirili BCC yöntemi ile yapılmıç analiz sonucunda elde edilen etkinlik skorları, türü ve referans değerleri Tablo 6'da gösterilmiştir. Çıktı yönelimli BCC modeli sonucunda 8 ülke etkin iken 11 ülke etkin olmamıştır. 
SEL, Measuring the Efficiency of Health System Developments in the Covid 19 Pandemic: A Study on the G-20, 181202.

Tablo 6. BCC Etkinlik Değeri, Türü ve Referans Değerleri

\begin{tabular}{llllllllllll}
\hline Ülke & Skor & $\begin{array}{l}\text { Etkinlik } \\
\text { Değeri }\end{array}$ & Etkinlin & $\begin{array}{l}\text { BRA } \\
(1)\end{array}$ & $\begin{array}{l}\text { CHN } \\
(6)\end{array}$ & $\begin{array}{l}\text { FRA } \\
(3)\end{array}$ & $\begin{array}{l}\text { GBR } \\
(8)\end{array}$ & $\begin{array}{l}\text { IDN } \\
(3)\end{array}$ & $\begin{array}{l}\text { IND } \\
(1)\end{array}$ & $\begin{array}{l}\text { TUR } \\
(5)\end{array}$ & $\begin{array}{c}\text { USA } \\
(4)\end{array}$ \\
\hline DEU & 0,51 & 1.95 & Değişken & - & - & 0.90 & 0.09 & - & - & - & 0.01 \\
USA & 1,00 & 1.00 & Değişken & - & - & - & - & - & - & - & 1.00 \\
ARG & 1,00 & 1.00 & Değişken & - & - & - & - & - & - & - & - \\
AUS & 0,36 & 2.77 & Değişken & - & 0.25 & - & 0.75 & - & - & - & - \\
BRA & 1,00 & 1.00 & Değişken & 1.00 & - & - & - & - & - & - & - \\
CHN & 1,00 & 1.00 & Değişken & - & 1.00 & - & - & - & - & - & - \\
IDN & 1,00 & 1.00 & Değişken & - & - & - & - & 1.00 & - & - & - \\
FRA & 1,00 & 1.00 & Değişken & - & - & 1.00 & - & - & - & - & - \\
ZAF & 1,00 & 1.00 & Değişken & - & - & - & - & - & - & - & - \\
KOR & 0,17 & 6.01 & Değişken & - & 0.52 & - & 0.42 & 0.06 & - & - & - \\
IND & 1,00 & 1.00 & Değişken & - & - & - & - & - & 1.00 & - & - \\
GBR & 1,00 & 1.00 & Değişken & - & - & - & 1.00 & - & - & - & - \\
ITA & 0,91 & 1.10 & Değişken & - & - & 0.22 & 0.14 & - & - & 0.46 & 0.19 \\
JPN & 0,10 & 10.21 & Değişken & - & 0.36 & 0.15 & 0.16 & - & - & 0.04 & 0.29 \\
CAN & 0,52 & 1.92 & Değişken & - & 0.01 & - & 0.55 & - & - & 0.37 & 0.07 \\
MEX & 0,42 & 2.38 & Değişken & 0.17 & - & - & - & - & 0.57 & 0.26 & - \\
RUS & 0,87 & 1.15 & Değişken & - & - & - & 0.37 & 0.46 & - & 0.17 & - \\
SAU & 0,67 & 1.49 & Değişken & - & 0.01 & - & 0.29 & 0.70 & - & - & - \\
TUR & 1,00 & 1.00 & Değişken & - & - & - & - & - & - & 1.00 & - \\
\hline & & & & & & & & & & & \\
\end{tabular}

Tablo 6 incelendiğinde Brezilya, Çin, Fransa, İngiltere, Endonezya, Hindistan, Türkiye ve ABD’nin etkin olduğu görülmüştür. En fazla referans alınan ülkeler ise ilk başta İngiltere (8), Çin(6), Türkiye (5) ve ABD (4) olmuştur. Çıktı değişkenleri sayısal olarak yüksek olsa bile oransal açıdan düşük olduğundan dolayı Hindistan ve Endonezya'nın etkin olduğu görülmüştür. En düşük etkinlik ise Japonya'da(0,098) belirlenmiştir. Tablo 7 'de çıktı yönelimli BCC yöntemine göre analiz sonuçları için değişkenlerin artık değerleri gösterilmiştir. 
SEL, Covid 19 Pandemisinde Sağlık Sistemi Gelişmelerinin Etkinliğinin Ölçülmesi: G-20 Üzerine Bir Inceleme, 181202.

Tablo 7. BCC için Değişkenlerin Artık Değerleri

\begin{tabular}{lcrrrrrrr}
\hline Ülke & G1 & \multicolumn{1}{c}{ G2 } & G3 & G4 & G5 & C-1 & C-2 & \multicolumn{1}{c}{ C-3 } \\
\hline DEU & 0.00 & 0.63 & 0.18 & 0.24 & 0.04 & 0.00 & 0.00 & 0.00 \\
AUS & 1.25 & 7.82 & 0.07 & 0.56 & 0.08 & 0.00 & 43845 & 0.00 \\
KOR & 0.00 & 17.89 & 0.67 & 0.14 & 0.01 & 0.00 & 12237 & 0.00 \\
ITA & 0.00 & 3.41 & 0.00 & 0.05 & 0.18 & 0.00 & 0.00 & 0.00 \\
JPN & 0.00 & 11.02 & 0.99 & 0.46 & 0.00 & 0.00 & 0.00 & 0.00 \\
CAN & 2.43 & 3.66 & 0.01 & 0.47 & 0.00 & 0.00 & 0.00 & 0.00 \\
MEX & 0.90 & 24.24 & 0.00 & 0.00 & 0.09 & 0.00 & 0.00 & 196032 \\
RUS & 0.00 & 8.14 & 0.70 & 0.49 & 0.26 & 0.00 & 0.00 & 0.00 \\
SAU & 0.00 & 29.07 & 0.08 & 0.14 & 0.11 & 0.00 & 4573 & 0.00 \\
\hline
\end{tabular}

Tablo 7 incelendiğinde ülkelerin etkin olabilmeleri için gereken girdilerdeki fazlalık ve çıktılardaki azlık değerleri gösterilmiştir. Örneğin üçüncü satırda yer alan KOR kodlu Güney Kore için G2, G3, G4 ve G5 girdi değişkenleri için fazlalık mevcut iken C-2 çıktı değişkeni için eksik olan değerler gösterilmiştir. Güney Kore'nin etkin olabilmesi en azından temel sağlık hizmeti alanların nüfusa oranında 17.890 birim, bin kişi başına düşen hastane yatakları 0.45, hemşire ve ebeleri 0.12 ile hekimleri 0.06 birim için daha etkin kullanmalıdır. Diğer ülkeler içinde satır değerleri incelenerek aynı yorumlar yapılabilir. Çıktılarda ise Covid 19 hastaları için milyon başına düşen iyileşen oranında Avustralya (43845), Güney Kore (12237) ve Suudi Arabistan'da (45739) artış olması gerekmektedir. Milyon kişi başına düşen test oranında ise Meksika'nın (196032) test sayılarını arttırmasına ihtiyaç vardır.

Ülkeler için ölçek etkinlik değerleri Tablo 8'de gösterilmiştir. Her sütun için ortalama değerlerden yüksek olan etkinlik değerleri renkli olarak gösterilmiştir.

Tablo 8. Ölçek Etkinlik Skorları

\begin{tabular}{lccc}
\hline Ülkeler & CCR & BCC & Ölçek Etkinliği Skoru \\
\hline DEU & 1,96 & 1,95 & 1,01 \\
USA & 1,00 & 1,00 & 1,00 \\
ARG & 1,00 & 1,00 & 1,00 \\
AUS & 3,01 & 2,77 & 1,09 \\
\hline
\end{tabular}


SEL, Measuring the Efficiency of Health System Developments in the Covid 19 Pandemic: A Study on the G-20, 181202.

\begin{tabular}{llll}
\hline BRA & 1,00 & 1,00 & 1,00 \\
CHN & 1,00 & 1,00 & 1,00 \\
IDN & 1,18 & 1,00 & 1,18 \\
FRA & 1,00 & 1,00 & 1,00 \\
ZAF & 1,03 & 1,00 & 1,03 \\
KOR & 6,17 & 6,01 & 1,03 \\
IND & 1,15 & 1,00 & 1,15 \\
GBR & 1,00 & 1,00 & 1,00 \\
ITA & 1,15 & 1,10 & 1,05 \\
JPN & 10,97 & 10,21 & 1,07 \\
CAN & 1,92 & 1,92 & 1,00 \\
MEX & 2,56 & 2,38 & 1,08 \\
RUS & 1,44 & 1,15 & 1,25 \\
SAU & 2,48 & 1,49 & 1,66 \\
\hline TUR & 1,00 & 1,00 & 1,00 \\
\hline Ortalama & 2,21 & 2,05 & 1,08 \\
\hline
\end{tabular}

Tablo 8 incelendiğinde CCR yöntemi sonucunda 5, BCC'de 4 ve ölçek etkinliği skorlarında 5 ülkenin ortalamanın üstünde olduğu görülmüştür. Uygulamaya konu olan ülke sayısı 19 tane olduğu dikkate alındığında sayıların az olduğu söylenebilir. ABD, Arjantin, Brezilya, Çin, Fransa, İngiltere ve Türkiye'nin ölçek etkinlik değerleri en yüksek değer olan bir olarak bulunmuştur. Diğer taraftan ölçek etkinliklerine göre Almanya, Avustralya, Endonezya, Güney Afrika, Güney Kore, Hindistan, İtalya, Japonya, Kanada, Meksika, Rusya ve Suudi Arabistan'ın etkin olmadıkları görülmüştür.

VZA uygulamasında CCR ve BCC modelleri ile elde edilen sonuçlar kullanılarak süper etkinlik değerleri hesaplanmıştır ve Tablo 9'da gösterilmiştir. Süper etkinlik değerleri hesaplanarak etkin ülkeler arasında en fazla etkin olanlar tespit edilmiştir.

Tablo 9. CCR ve BCC için Süper Etkinlik Değerleri

\begin{tabular}{lclc}
\hline Ülke & CCR & Ülke & BCC \\
\hline CHN & 36,98 & CHN & 25,93 \\
\hline
\end{tabular}


SEL, Covid 19 Pandemisinde Sağlık Sistemi Gelişmelerinin Etkinliğinin Ölçülmesi: G-20 Üzerine Bir Inceleme, 181202.

\begin{tabular}{llll}
\hline GBR & 2,74 & USA & 3,45 \\
TUR & 1,55 & GBR & 3,14 \\
ARG & 1,40 & IDN & 2,93 \\
USA & 1,12 & ARG & 2,29 \\
BRA & 1,12 & IND & 1,61 \\
FRA & 1,04 & TUR & 1,59 \\
& & FRA & 1,28 \\
& & BRA & 1,13 \\
& & ZAF & 1,02 \\
\hline
\end{tabular}

Tablo 9 incelendiğinde CCR ve BCC modeli için en fazla etkin olan ülke açık ara fark ile Çin olduğu görülmektedir. Türkiye ise her iki değerlendirme sonucunda da en fazla etkin olan ülkeler arasında yer almıştır. Süper etkinlik sonuçlarına göre iki değerlendirme içinde Avustralya, Güney Kore ve Japonya sonra sıralarda yer almıştır.

\section{Tartışma ve Sonuç}

Dünya nüfusunun 2/3'ünü tesmsil eden G-20 ülkelerinin 2000-2018 yıllarındaki sağlık göstergeleri ortalamaları kullanılarak Covid 19 performansları VZA ile değerlendirilmiştir. Çalışmada girdi değişkenleri; mevcut sağlık harcamaları (GSYiH göre \%), en azından temel sağlık hizmetlerini kullanan kişiler (nüfusun \%), hastane yatakları (1.000 kişi başına), hemşireler ve ebeler (1000 kişi başına), hekimler (1000 kişi başına) iken çıktı değişkenleri; milyon kişi başına ölüm, iyileşen ve test oranları kullanılmıştır. Etkinlik analizi için çıktı yönelimli CCR ve BCC yöntemleri kullanılmıştır. Elde edilen CCR ve BCC değerleri ile etkinlik ölçek skorları ve süper etkinlik değerleri hesaplanmıştır.

Çıktı yönelimli CCR modeli sonuçları incelendiğinde Brezilya, Çin, Fransa, İngiltere, Türkiye ve $A B D^{\prime}$ nin etkin olduğu görülmüştür. Çıktı yönelimli BCC modeli sonuçları incelendiğinde CCR modelini sonuçlarına ek olarak Endonezya ve Hindistan’ın eklendiği görülmüştür. Her iki model içinde etkin olan 6 ülkenin ortak özellikleri incelenmiştir. Buna göre ortalamalar incelendiğinde girdi değişkenleri için 6 ülkenin 4'ünde G-1: mevcut sağlık harcamaları (GSYIH göre \%) ve 3'ünde G-4: hemşireler ve ebeler (1000 kişi başına) ile G-5: hekimler (1000 kişi başına) değerlerinin yüksek olduğu görülmüştür. Çıktılar için incelendiğinde 6 ülkenin 3'ünde C-2: milyon kişi başına iyileşen oranı ve C-3: milyon kişi başına test oranlarının yüksek olduğu belirlenmiştir. Etkin olmayan ülkeler için mevcut sağlık harcamalarını yükseltmeleri ile hemşire, ebe ve hekim sayılarının etkin olarak kullanılması gerektiği söylenebilir. Ayrıca hastalığın ilerlemeden önce teşhis edilebilmesi için gerekli test sayılarının arttırılması iyileşenlerin sayılarının da yükselmesine neden olacaktır. 
SEL, Measuring the Efficiency of Health System Developments in the Covid 19 Pandemic: A Study on the G-20, 181202.

Uygulamalar sonucunda CCR ve BCC modelleri için etkin olmayan ülkelerin referans alabileceği ülkelerin Çin, İngiltere, Türkiye ve ABD olduğu tespit edilmiştir. Özellikle süper etkinlik değerleri incelendiğinde Çin diğer ülkelerin önüne geçmektedir. Virüsün çıkış ve yayıldığı nokta olan Çin'in performans değerlendirmesinde etkin olarak çıkması geçmiş dönem sağlık sistemi ve toplumsal alanda yaptığı yatırım ve gelişmelerin sonucudur. Süper etkinlik sonuçlarına göre iki değerlendirme içinde Avustralya, Güney Kore ve Japonya son sıralarda yer almıştır.

Benzer çalışmalar incelendiğinde Selamzade ve Özdemir (2020) çalışması için OECD ülkelerinin etkinlikleri araştırılmıştır. Sonuçlar karşılaştırıldığında ortak olan ülkeler için Türkiye etkin olarak bulunmuştur. Etkin olmayan ülkeler için önerilen iyileştirmeler ise birbirine yakın sonuçlar verdiği gözlenmiştir. Çalışmanın yapıldığı tarih ve salgının yayılma durumu ile değişkenler göz önüne alındığında var olan farklılıkların normal olduğu görülmüştür.

Sonraki araştırmalar için girdi ve çıktı değişkenleri değiştirilerek farklı yöntemler ile ülkelerin performansları değerlendirilebilir. Özellikle salgının bitiminde kesin değerlere ulaşılabileceğinden dolayı elde edilen sonuçlarda değişiklik görülebilir. Ancak özellikle girdi değişkenleri için sağlık hizmetlerinin alt yapısı ve bu alandaki yatırımların her dönemde ülkelerin performansınında belirleyici rol alacağı açıktır.

\section{"Covid 19 Pandemisinde Sağlık Sistemi Gelişmelerinin Etkinliğinin Ölçülmesi: G-20 Üzerine Bir İnceleme" Başlıklı Makalenin Araştırma ve Etik Beyanı Bilgileri}

Bu çalışma "Araştırma ve Yayın Etiği" değerlerine uygun olarak hazırlanmıştır.

Bilgilendirme

Yazar Çıkar Çatışması Beyanı

Yazar Katkı Oranı Beyanı

Teşekkür

Etik Kurul Onay Belgesi
Çalışma herhangi bir bildiri veya tez benzeri çalışmadan üretim değildir.

Çalışmada herhangi bir çıkar çatışması bulunmamaktadır.

Çalışmayı şahsım Ahmet SEL olarak tek başıma hazırladığımı beyan ederim.

Çalışmada teşekkür gerektiren bir durum bulunmamaktadır.

Çalışmada etik kurul onayı gerekmemektedir. 
SEL, Covid 19 Pandemisinde Sağlık Sistemi Gelişmelerinin Etkinliğinin Ölçülmesi: G-20 Üzerine Bir Inceleme, 181202.

\section{Kaynakça}

Arslan, i. (2020). Küresel Bir Tehdit (COVID-19 Salgını) ve Değişime Yolculuk. Üsküdar Üniversitesi Sosyal Bilimler Dergisi, (10), 1-36.

Banker, R. D., Charnes, A., \& Cooper, W. W. (1984). Some Models For Estimating Technical And Scale Inefficiencies in Data Envelopment Analysis. Management Science, 30(9), 1078-1092.

BOZ C. \& ÖNDER, E. (2017). OECD Ülkelerinin Sağlık Sistemi Performanslarının Değerlendirilmesi. Sosyal Güvence, (11), 24-61.

Charnes, A., Cooper, W. W., \& Rhodes, E. (1978). Measuring The Efficiency Of Decision Making Units. European journal of operational research, 2(6), 429-444.

Charnes, A., Cooper, W., Lewin, A. Y., \& Seiford, L. M. (1997). Data Envelopment Analysis Theory, Methodology And Applications. Journal of the Operational Research society, 48(3), 332-333.

Cooper, W. W., Seiford, L. M., \& Zhu, J. (2011). Data Envelopment Analysis: History, Models, And Interpretations. In Handbook On Data Envelopment Analysis (pp. 1-39). Springer, Boston, MA.

Hadad, S., Hadad, Y., \& Simon-Tuval, T. (2013). Determinants Of Healthcare System's Efficiency in OECD Countries. The European Journal Of Health Economics, 14(2), 253-265.

Kocaman, A. M., Mutlu, M., Bayraktar, D. \& Araz, Ö. M., (2012). OECD Ülkelerinin Sağlık Sistemlerinin Etkinlik Analizi. Endüstri Mühendisliği Dergisi, 23(4), 14-31.

Konca, M., \& Demirci, Ş. (2019). G20 Ülkeleri ve Türkiye'nin Sağlık Sistemi Performansı: Yıllara Göre Karşılaştırmalı Bir Analiz. Anemon Muş Alparslan Üniversitesi Sosyal Bilimler Dergisi, 7(4), 175-181.

Konca, M., Gözlü, M., \& Çakmak, C. (2019). G-20 Ülkelerinin Sağlık Harcamaları Yönünden Etkinliğinin Değerlendirilmesi. Verimlilik Dergisi, 2019/2, 119-141

Murray, C. J., \& Frenk, J. (2000). A Framework For Assessing The Performance Of Health Systems. Bulletin Of The World Health Organization, 78, 717-731.

Özden, Ü. (2008). Veri Zarflama Analizi (VZA) İle Türkiye'deki Vakıf Üniversitelerinin Etkinliğinin Ölçülmesi. İstanbul Üniversitesi İşletme Fakültesi Dergisi, 37(2), 167185.

Samut, P. K., \& Cafri, R. (2016). Analysis Of The Efficiency Determinants Of Health Systems in OECD Countries by DEA and Panel Tobit. Social Indicators Research, 129(1), 113132.

Selamzade, F., \& Özdemir, Y. (2020). COVID-19a Karşı OECD Ülkelerinin Etkinliğinin VZA ile Değerlendirilmesi. Electronic Turkish Studies, 15(4), 977-991. 
SEL, Measuring the Efficiency of Health System Developments in the Covid 19 Pandemic: A Study on the G-20, 181202.

Shirouyehzad, H., Jouzdani, J., \& Khodadadi Karimvand, M. (2020). Fight Against COVID-19: A Global Efficiency Evaluation Based On Contagion Control And Medical Treatment. Journal of Applied Research on Industrial Engineering, 7(2), 109-120.

Şahinbaş, F., Konca, M. \& Yetim, B. (2019). OECD Ülkelerinde Sağlık Hizmetleri Etkinliğinin Değerlendirilmesi. 3. Uluslararası 13. Ulusal Sağlık ve Hastane Idaresi Kongresi. 366-372.

Teleş, M., Çakmak, C., \& Konca, M. (2018). Avrupa Birliği Döngüsündeki Ülkelerin Sağlık Sistemleri Performanslarının Karşılaştırılması. Yönetim ve Ekonomi: Celal Bayar Üniversitesi Iktisadi ve Idari Bilimler Fakültesi Dergisi, 25(3), 811-835.

Temür, Y. \& Bakırcı, F. (2008). Türkiye'de Sağlık Kurumlarının Performans Analizi: Bir Vza Uygulamasi. Sosyal Bilimler Dergisi, 10(3), 262.

Türk Tabibler Birliği, (2020). Covid-19 Pandemisi İki Aylık Değerlendirme Raporu. Retrieved on, 22, 2020.

World Health Organization (WHO). (2000). The World Health Report 2000: Health Systems: Improving Performance. World Health Organization. Switzerland-Geneva: WHO Publication.

Yeşilyurt, Ö., \& Salamov, F. (2017). Türk Devletleri Sağlık Sistemlerinde Etkinliğin Ve Etkinliğe Etki Eden Faktörlerin Süper Etkinlik Ve TOBIT Modelleriyle Değerlendirilmesi. In III. IBANESS Congress Series-Edirne/Turkey (pp. 852-863). 


\title{
Measuring the Efficiency of Health System Developments in the Covid 19 Pandemic: A Study on the G-20
}

\author{
Ahmet SEL
}

\section{Extended Abstract}

In addition to economic, social, and cultural factors, the structure of health systems is now used as an important criterion in determining a country's level of development and socioeconomic development (Temür \& Bakirci, 2008, p.262). The structure of health services determines the main foundation of social progress and development. It is easier for societies whose individuals grow up healthy in every way to keep up with the times in the fields of education and technology. Countries that produce and develop technology in the field of health are seen to have high competencies in other areas as well.

On December 31, 2019, the Covid 19 disease was discovered for the first time in Wuhan, China. While previous types of the corona virus caused people to catch a cold, it was discovered that they caused severe discomfort in this epidemic. The virus causes pneumonia that is resistant to treatment, particularly in patients; it has been determined that it is a new species known as SARS-CoV-2. It has been determined that the virus, which cannot be determined from which animal it is transmitted, is quickly transmitted from person to person. The World Health Organization declared a global epidemic on March 11, 2020, due to an increase in pandemic rates and an inability to prevent contamination.

While the rapid spread of the Covid 19 epidemic affected all countries, it created difficult conditions for those that were unprepared for the pandemic. Managers switched to full closure when mask and distance measures were insufficient, fearing that their health systems were insufficient. During this process, it has been discovered that not only the countries' health systems, but also their economic and social development levels, are effective in pandemic management. In this regard, health indicators included in the World Bank database provide a wide range for evaluating countries' health systems. The effectiveness of health systems in the Covid 19 pandemic process was investigated using past health indicators from G-20 countries, including Turkey.

In this study, Covid 19 performance was evaluated using G-20 country averages of health indicators from 2000 to 2018. In practice, the G-20 countries are chosen because the G-20, which represents approximately 85 percent of the world economy, 75 percent of its trade, and two-thirds of its population, is an international with its inclusive structure that brings together developed and emerging economies from different continents on the same 
platform. It manifests itself as an entity with a rising economic profile (Ministry of Foreign Affairs, 2020). Current healthcare spending (percentage of GDP), people receiving at least primary health care (percentage of population), hospital beds (per 1,000 inhabitants), nurses and midwives (per 1,000 inhabitants), physicians (per 1,000 inhabitants), and output deaths per million inhabitants rate, recovery rate per million people, and test rate per million people were used as inputs in the study. For efficiency analysis, output-oriented Charnes, Cooper, Rhodes (CCR) and variable scale Banker, Charnes, Cooper (BCC) methods were used. With the obtained CCR and BCC values, efficiency scale scores and super efficiency values were calculated. In the final section, suggestions for improving inefficient countries are made. In the final section, suggestions for improving inefficient countries are presented.

DEA is one of the most effective methods for evaluating performance. It takes one of two approaches: fixed return to scale (CCR) or variable return to scale (VRS) (BCC). The CCR model examines the increase in output caused by increases in inputs. The BCC model investigates the more or less increase in output that may occur as a result of an increase in inputs. Furthermore, according to the type of orientation, both approaches have subsections called input, output, and non-oriented.

Despite the fact that the European Union is a member of the G-20, 19 countries have been included in the application since the countries are being evaluated. The World Bank database contains 250 variables categorized as health indicators. As input variables, the average values of five different indicators in ratio and percentage format between 2000 and 2018 that did not contain missing data were used.

When the output-oriented CCR model results are examined, Brazil, China, France, England, Turkey, and America are found to be effective. When the output oriented BCC model results were examined, it was discovered that Indonesia and India had been added to the CCR model results. The similarities and differences between six countries that participate in both models have been investigated. As a result, when averages for input variables are examined, G-1 values were found to be high in four of six countries: current health expenditures (percentage of GDP), G-4: nurses and midwives (per 1000 people), and G-5: physicians (per 1000 people). When outputs were examined, it was discovered that C-2: recovery rate per million people and $\mathrm{C}$-3: test rates per million people were both high in three of six countries. It is possible to argue that the number of nurses, midwives, and physicians should be increased by increasing current health expenditures for inefficient countries. Furthermore, increasing the number of tests that result in early disease diagnosis will result in an increase in the number of people who recover. As a result of the applications, countries that are ineffective for CCR and BCC models include China, England, Turkey, and the United States. China outperforms other countries, particularly when super efficiency values are considered. The effective emergence of China, the origin and spread of the virus, in performance evaluation is the result of previous investments and developments in the health system and social field. 